\title{
Presentación del monográfico
}

A pesar de la eterna transversalidad de la educación sexual y de su irrupción en la década de los 90 gracias a la LOGSE y a los esfuerzos históricos por parte de organismos internacionales como la UNESCO o la OMS, la educación sexual sigue siendo una asignatura pendiente en el contexto español. Las diversas reformas legislativas en materia de educación no han conseguido darle un espacio sostenido y estable a este contenido, que sigue envuelto en una polémica que obedece a intereses extra pedagógicos y que está ralentizando su aplicación real. Si bien todavía no tenemos todas las certezas necesarias sobre la aplicación de la Ley Orgánica 3/2020, de 29 de diciembre, por la que se modifica la LOE de 2006, parece que nos enfrentamos a un nuevo escenario a priori más positivo para esta materia. Estamos en un momento clave para la definición del concepto y sus implicaciones pedagógicas, y tenemos la oportunidad de plantear un enfoque epistemológico que ofrezca una respuesta transformadora, inclusiva y con espíritu crítico.

Uno de nuestros objetivos prioritarios es arrojar luz sobre la definición de educación sexual. Entendemos la educación sexual como un cuerpo de contenidos basado en evidencias científicas y orientado a ofrecer una atención socioeducativa a las sexualidades, abordando todos los hechos de diversidad, especialmente lo que concierne al colectivo LGTBIQ+. Debe estar adaptado y secuenciado en base a las diferentes etapas del desarrollo y superar la mera prevención sanitaria. Así mismo, se plantea que el acceso a información y orientación en esta materia es un derecho humano irrenunciable en favor del cual agentes sociales, políti- cos y educativos deben aunar esfuerzos comunes. Más allá de su concreción en políticas específicas, legislación vigente como la Ley Orgánica $1 / 2004$, de 28 de diciembre, de medidas de protección integral contra la violencia de género o la Ley Orgánica $2 / 2010$, de 3 de marzo, de salud sexual y reproductiva y de la interrupción voluntaria del embarazo amparan esta concepción. Superando la normativa legal, las metas vinculadas a los Objetivos de Desarrollo Sostenible (ODS 3,4 y 5) expresan explícitamente supuestos que encajan con esta concepción de educación sexual con perspectiva de género.

Si bien parte relevante de nuestros esfuerzos van encaminados al desarrollo de ese entramado conceptual y didáctico no podemos obviar la importancia de su transferencia, especialmente en lo que a formación inicial y continua del profesorado de todas las etapas se refiere. Es poco coherente pretender la estabilidad y universalización de la educación sexual como contenido curricular obligatorio sin abordar la complejidad de los planes formativos relacionados con la función docente o las iniciativas públicas, privadas y del tercer sector que tratan de establecer directrices en esta línea. Materiales y recursos, iniciativas de innovación y planteamientos metodológicos son, sin duda, componentes esenciales que debemos considerar.

En este monográfico presentaremos investigaciones y planteamientos emergentes en torno a una educación sexual feminista, despatologizada y en positivo, que nos permitirán establecer las bases para su inclusión en el currículo educativo atendiendo a motivaciones científicas y didácticas. 